\title{
Efisiensi Teknis Usahatani Kopi Arabika di Kabupaten Enrekang
}

\section{The Technical Efficiency of Arabica Coffee Farming in the District Enrekang}

\author{
Syahruni Thamrin $^{1}$, Slamet Hartono ${ }^{2}$, Dwidjono Hadi Darwanto ${ }^{2}$, Jamhari $^{2}$ \\ ${ }^{1}$ Politeknik Pertanian Negeri Pangkep \\ ${ }^{2}$ Fakultas Pertanian Universitas Gadjah Mada
}

\begin{abstract}
This study was aimed to determine g. Population of this study are the arabica coffee farmers, farmer sample size of 100 respondents. The analysis was done by descriptive analysis qualitative, analysis of technical efficiency and technical inefficiencies. Estimation was done by using stochastic frontier production function. The factors which significantly influence to the technical efficiency of the coffee are the use of land, Urea, ZA and labor. The average technical efficiency of farmer respondents was 0.89 , meaning farmers are technically efficient especially in terms of resource allocation and utilization of existing cultivation technology. While the results of estimation with MLE method, variables that significantly and negatively correlated to the amount of family members.
\end{abstract}

Keywords: Technical Efficiency, Stochastic Frontier, Production Function, Coffee Farming

\section{INTISARI}

Penelitian ini bertujuan untuk mengetahui efisiensi teknis usahatani kopi arabika di Kabupaten Enrekang. Populasi dari penelitian ini adalah petani kopi arabika, jumlah sampel dalam penelitian ini sebanyak 100 orang. Analisis dilakukan dengan analisis deskriptif kualitatif, analisis efisiensi teknis dan inefisiensi teknis. Estimasi dilakukan dengan menggunakan fungsi produksi frontir stokastik. Faktor-faktor yang berpengaruh sangat nyata pada efisiensi teknis kopi adalah luas lahan, penggunaan pupuk Urea, ZA dan tenaga kerja. Rata-rata efisiensi teknis petani responden adalah 0,89 . Berarti petani telah efisien secara teknis khususnya dalam mengalokasikan sumberdaya dan memanfaatkan teknologi budidaya yang ada. Sementara itu hasil estimasi dengan menggunakan metode MLE, variable yang signifikan dan berkorelasi negatif adalah jumlah anggota keluarga.

Kata kunci: Efisiensi Teknis, Fungsi Produksi Frontir Stokastik, Usahatani Kopi

\section{PENDAHULUAN}

Kopi merupakan salah satu komoditas perkebunan yang mempunyai peran cukup penting dalam kegiatan perekonomian di Indonesia. Hal ini karena kopi telah memberikan sumbangan yang cukup besar bagi devisa negara, menjadi ekspor non migas, selain itu dapat menjadi penyedia lapangan kerja dan sumber pendapatan bagi petani pekebun kopi maupun bagi pelaku ekonomi lainnya yang terlibat dalam budidaya, pengolahan, maupun dalam mata rantai pemasaran.

Sulawesi Selatan merupakan salah satu propinsi di Kawasan Timur Indonesia yang memiliki potensi pengembangan kopi. Hal ini ditunjukkan dengan areal penanaman yang cukup luas serta keadaan agroklimatologi yang sangat mendukung. Pada rentang waktu tahun 1977 2002, produksi kopi Sulawesi Selatan mencapai 202.165,50 ton kopi robusta dan 15.619 kopi arabika. Lokasi produksinya tersebar pada tujuh kabupaten. Produksi kopi robusta di atas 1000 ton/tahun dihasilkan di Kabupaten Bulukumba, Bantaeng, Sinjai, Pinrang, Luwu, Lutra dan Toraja. Sementara kopi arabika di Kabupaten Toraja, Enrekang dan Gowa yang produksinya juga masing-masing mencapai di atas 1000 ton/tahun (Alam, 2006). Kopi arabika yang dihasilkan oleh Kabupaten Tana Toraja dan Kabupaten Enrekang di Sulawesi Selatan ini sudah dikenal luas di luar negeri dengan nama Kopi Toraja dan Kopi Kalosi.

Di Kabupaten Enrekang tercatat sekitar 1480 
ha dari total area 10.444 ha merupakan tanaman berumur lanjut yang perlu untuk diremajakan. Tanpa usaha peremajaan Kabupaten Enrekang akan kehilangan pertanaman kopi arabika sekitar 1480 ha. Setara dengan produksi tidak kurang dari 1.036 ton atau kehilangan penerimaan sebesar US \$ 1,15 juta/tahun (Disbun Enrekang, 2005).

Di Kabupaten Enrekang sendiri, upaya yang dilakukan dalam pengembangan kopi ini adalah intensifikasi dan perluasan tanaman kopi, pembinaan petani dan penguatan kelompok tani melalui petugas pendamping, pengadaan sarana dan prasarana serta paket teknologi yang bebas dari bahan kimia. Salah satu permasalahan dalam pengembangan kopi arabika adalah pembudidayaan yang masih dilakukan secara tradisional oleh masyarakat setempat dan belum sepenuhnya menerapkan teknologi budidaya tanaman kopi. Akibat penanganan on farm dan off farm yang belum memadai, produk yang dihasilkan didominasi biji asalan sehingga berpengaruh terhadap rendahnya mutu kopi. Di samping itu, diversifikasi produk kopi olahan belum berkembang, sehingga dengan keberadaan petugas pendamping, para petani tergerak untuk menerapkan teknologi budidaya tanaman kopi secara modern.

Berdasarkan uraian di atas maka dilakukan penelitian ini untuk mengestimasi tingkat efisiensi teknis dan faktor-faktor yang mempengaruhi usahatani kopi Arabika di

$$
y i=f(x 1, \beta) \varepsilon^{\varepsilon i}
$$

Keterangan:

yi $=$ keluaran yang dihasilkan oleh observasi kei

$\mathrm{x} 1 \mathrm{i}=$ vektor masukan $\mathrm{L}$ yang digunakan oleh observasi ke-i

$\beta=$ vektor koefisien parameter

$\varepsilon_{\mathrm{i}}=$ "galat khusus" dari observasi ke-i

$=\mathrm{v}_{\mathrm{i}}-\mathrm{u}_{\mathrm{i}}:$ error term $\left(\mathrm{u}_{\mathrm{i}}=\right.$ efek inefisiensi teknis dalam model)

Variabel sisa (random shock) vi merupakan variable acak yang menggambarkan ukuran kesalahan dalam produksi yang disebabkan oleh faktor eksternal dan tidak dapat dikontrol oleh petani. Variabel acak vi secara identik terdistribusi normal (iid.) dan ragamnya konstan $\left(\mathrm{vi} \approx \mathrm{N}\left(0, \sigma \mathrm{v}^{2}\right)\right)$. Variabel kesalahan (residual solow) ui adalah variable acak yang kabupaten Enrekang.

\section{BAHAN DAN METODE}

Penelitian dilaksanakan di Kabupaten Enrekang, dengan pertimbangan merupakan sentra produksi kopi Arabika di Propinsi Sulawesi Selatan. Lokasi penelitian ditentukan secara purposive sampling, dan lokasi yang dipilih yaitu Desa Baroko dan Desa Benteng Alla Kecamatan Alla, dengan pertimbangan merupakan salah satu daerah sentra pengembangan kopi Arabika terbesar, selain itu jumlah tanaman yang produktif lebih banyak disbanding kecamatan lain yang juga merupakan sentra pengembangan kopi.

Kriteria petani sampel adalah rumahtangga petani yang melaksanakan usahatani kopi arabika. Penentuan sampel dilakukan dengan metode random sampling. Jumlah sampel yang diambil sebanyak 100 sampel petani dan terdistribusi secara merata pada kedua desa tersebut.

Pengukuran efisiensi teknis usahatani kopi di Kabupaten Enrekang dengan menggunakan stochastic frontier model dikemukakan secara terpisah oleh Aigner et al. (1977) dan Meeusen dan van den Broeck (1977) diacu dalam Coelli dan Battesse (1998) persamaan fungsi produksi yang dispesifikasi untuk data silang (crosssectional data) yang mempunyai dua komponen error term, yaitu vi dan ui. Stochastic frontier model dapat dituliskan sebagai berikut :

menggambarkan inefisiensi teknis di dalam produksi dan berkaitan dengan faktor internal, di mana semakin besar nilai ui, maka semakin besar pula inefisiensi usahatani yang dilakukan petani. Variabel acak ui tidak boleh bernilai negative dan distribusinya setengah normal dengan nilai distribusi $\left|\mathrm{N}\left(\mathrm{i}, \mathrm{\sigma u}^{2}\right)\right|($ Coelli dan Battese, 1998). Pendugaan parameter fungsi produksi dan fungsi inefisiensi dilakukan secara simultan dengan program FRONTIER 4.1c (Coelli, 1996).

Aigner et al. (1977) dan Jondrow et al. (1982) mendefinisikan $\sigma^{2}=\sigma_{\mathrm{v}}{ }^{2}+\sigma_{\mathrm{u}}{ }^{2}$ dan $\lambda=\frac{\sigma_{u}}{\sigma_{v}}$. Sementara menurut Sementara menurut Battese dan Corra (1977) yang menggantikan $\sigma_{v}^{2}$ dan $\sigma_{u}^{2}$ dengan $\sigma^{2}=\sigma_{v}{ }^{2}+\sigma_{u}{ }^{2}$ dan $\gamma=\sigma_{u}{ }^{2} /\left(\sigma_{v}^{2}+\sigma_{u}^{2}\right)$. Ini dilakukan dengan perhitungan maximum likelihood estimates (MLE). 
Tingkat efisiensi teknis dapat dihitung dengan menggunakan persamaan berikut :

$$
\mathrm{ET}_{\mathrm{i}}=\frac{Y_{i}}{\exp \left(X_{i} \beta\right)}==\frac{\exp \left(X_{i} \beta-U_{i}\right)}{\exp \left(X_{i} \beta\right)}=\exp (-\mathrm{U})_{i}
$$

Tingkat efisiensi teknis (ET) untuk masing-masing individu diperoleh dari hasil perbandingan antara tingkat aktual output, $\mathrm{Y}_{\mathrm{i}}$, dengan tingkat predicted output, $\exp \left(\mathrm{X}_{\mathrm{i}}, \beta\right)$.

Model frontir stokastik yang digunakan dalam penelitian ini adalah:

$\ln \mathrm{y}=\alpha_{0}+\alpha_{1} \ln \mathrm{x}_{1}+\alpha_{2} \ln \mathrm{x}_{2}+\alpha_{3} \ln \mathrm{x}_{3}+\alpha_{4} \ln \mathrm{x}_{4}+\alpha_{5} \ln \mathrm{x}_{5}+\alpha_{6} \ln \mathrm{x}_{6}+\alpha_{7} \ln \mathrm{x}_{7}+\alpha_{8} \ln \mathrm{x}_{8}+\alpha_{9} \ln \mathrm{x}_{9}+\alpha_{10}$ $\ln \mathrm{x}_{10}+\ldots+\left(\mathrm{v}_{\mathrm{i}}-\mathrm{u}_{\mathrm{i}}\right)$

keterangan:

y : produksi kopi Arabika per luas lahan $(\mathrm{kg} / \mathrm{ha})$

$\mathrm{x}_{1}$ : luas lahan (ha)

$\mathrm{x}_{2}$ : kerapatan tanaman (jumlah pohon/ha)

$\mathrm{x}_{3}$ : pupuk Urea per luas lahan $(\mathrm{kg} / \mathrm{ha})$

$\mathrm{x}_{4}$ : pupuk ZA per luas lahan ( $\left.\mathrm{kg} / \mathrm{ha}\right)$

$\mathrm{x}_{5}$ : pupuk SP36 per luas lahan $(\mathrm{kg} / \mathrm{ha})$

$\mathrm{x}_{6}$ : pupuk $\mathrm{KCl}$ per luas lahan $(\mathrm{kg} / \mathrm{ha})$

$\mathrm{x}_{7}$ : pestisida per luas lahan (ltr/ha)

$\mathrm{x}_{8}$ : herbisida per luas lahan (ltr/ha) $\mathrm{x}_{9}$ : pupuk kandang per luas lahan $(\mathrm{kg} / \mathrm{ha})$

$\mathrm{x}_{10}$ : tenaga kerja per luas lahan (HOK/ha)

$\alpha_{0}$ : intersep

$\alpha_{\mathrm{i}}$ : koefisien parameter penduga, di mana $\mathrm{i}=$ $1,2,3, . ., 10$

$\mathrm{v}_{\mathrm{i}}-\mathrm{u}_{\mathrm{i}}$ : error term (ui $=$ efek inefisiensi teknis dalam model)

Untuk menentukan nilai parameter distribusi (ui) efek inefisiensi teknis pada penelitian ini digunakan rumus sebagai berikut:

$$
\mathrm{i}=\delta_{0}+\delta_{1} \mathrm{Z}_{1}+\delta_{2} \mathrm{Z}_{2}+\delta_{3} \mathrm{Z}_{3}+\delta_{4} \mathrm{Z}_{4}+\delta_{5} \mathrm{Z}_{5}
$$

Keterangan:

$\mathrm{i}=$ efek in efisiensi teknis

$\mathrm{Z}_{1} \quad=$ umur petani (tahun)

$\mathrm{Z}_{2}$ = pengalaman berusahatani kopi (tahun)

$\mathrm{Z}_{3}$ = pendidikan formal (tahun)

$\mathrm{Z}_{4} \quad$ = jumlah anggota keluarga (tahun)

$Z_{5}=$ lama bergabung dalam kelompok tani (tahun)

Tanda yang diharapkan untuk masing-masing parameter efek inefisiensi $\delta 1$ sampai dengan $\delta 5$ diatas adalah negatif.

Parameter dari model diatas diestimasi dengan metode maximum likelihood (MLE) dengan memakai program komputasi frontier versi 4.1 yang dikembangkan oleh Coelli (1996).

\section{HASIL DAN PEMBAHASAN}

\section{Analisis Produksi}

Hasil estimasi fungsi produksi frontir stokastik pada usahatani kopi di Kabupaten Enrekang seperti terlihat pada Tabel 1 memperlihatkan bahwa terdapat 3 (tiga) faktor yang berpengaruh sangat nyata (pada tingkat kepercayaan 99\%). Untuk lebih jelasnya dapat dilihat pada Tabel 1.

Berdasarkan hasil estimasi fungsi produksi stochastic frontier, terdapat enam faktor yang berpengaruh terhadap produksi kopi Arabika. Empat faktor diantaranya, yaitu luas lahan, pupuk urea, pupuk ZA, dan penggunaan tenaga kerja berpengaruh sangat nyata pada taraf kepercayaan 99\% terhadap produksi kopi, dan dua faktor lainnya yaitu pupuk SP36 dan herbisida berpengaruh nyata pada taraf kepercayaan $90 \%$. Hal ini berarti penambahan input- input ini berdampak pada peningkatan produksi kopi.

Model fungsi produksi stochastic frontier usahatani kopi dijabarkan dalam persamaan berikut:

Ln $Y=3,180_{(0,520)}-0,048_{(0,063)} \ln X_{1}+0,014_{(0,054)} \ln X_{2}+0,190_{(0,071)} \ln X_{3}+0,197_{(0,030)} \ln X_{4}+0,094_{(0,050)} \ln X_{5}$ $+0,009_{(0,073)} \ln X_{6}+0,042_{(0,042)} \ln X_{7}+0,088_{(0,037)} \ln X_{8}+0,032_{(0,039)} \ln X_{9}+0,343_{(0,085)} \ln X_{10}+V_{i}-U_{i}$

Nilai koefisien variabel lahan adalah (0,048), hal ini berarti luas lahan tidak berkorelasi positif dalam peningkatan produksi kopi. Ekstensifikasi bukan cara terbaik dalam peningkatan produksi kopi karena penambahan luas lahan sebesar $1 \%$ akan mengakibatkan penurunan produksi kopi sebesar 0,048. Jadi yang perlu dilakukan adalah mengintensifkan 
pemanfaatan lahan guna peningkatan produksi.

Penggunaan pupuk Urea dalam usahatani kopi menunjukkan bahwa penambahan jumlah Urea sebesar satu persen hanya akan meningkatkan produksi kopi sebesar 0,190 persen, cateris paribus. Penambahan pupuk ZA sebesar satu persen akan meningkatkan produksi sebesar 0,197 persen, cateris paribus. Meskipun tidak responsif tapi penambahan pupuk ZA berdampak signifikan terhadap produksi. Hal ini disebabkan karena zat-zat yang terdapat dalam pupuk Urea dan pupuk ZA sangat diperlukan tanaman untuk meningkatkan produksinya. Demikian juga halnya dengan penggunaan pupuk SP36, penggunaan pupuk ini hanya akan meningkatkan produksi sebesar 0,094, cateris paribus. Meskipun tidak responsif tapi penggunaan pupuk ini memberikan dampak yang signifikan terhadap produksi.

Tabel 1. Hasil Maximum Likelihood Estimated (MLE) Model Fungsi Produksi Stochastic Frontier Usahatani Kopi Kalosi di Kabupaten Enrekang

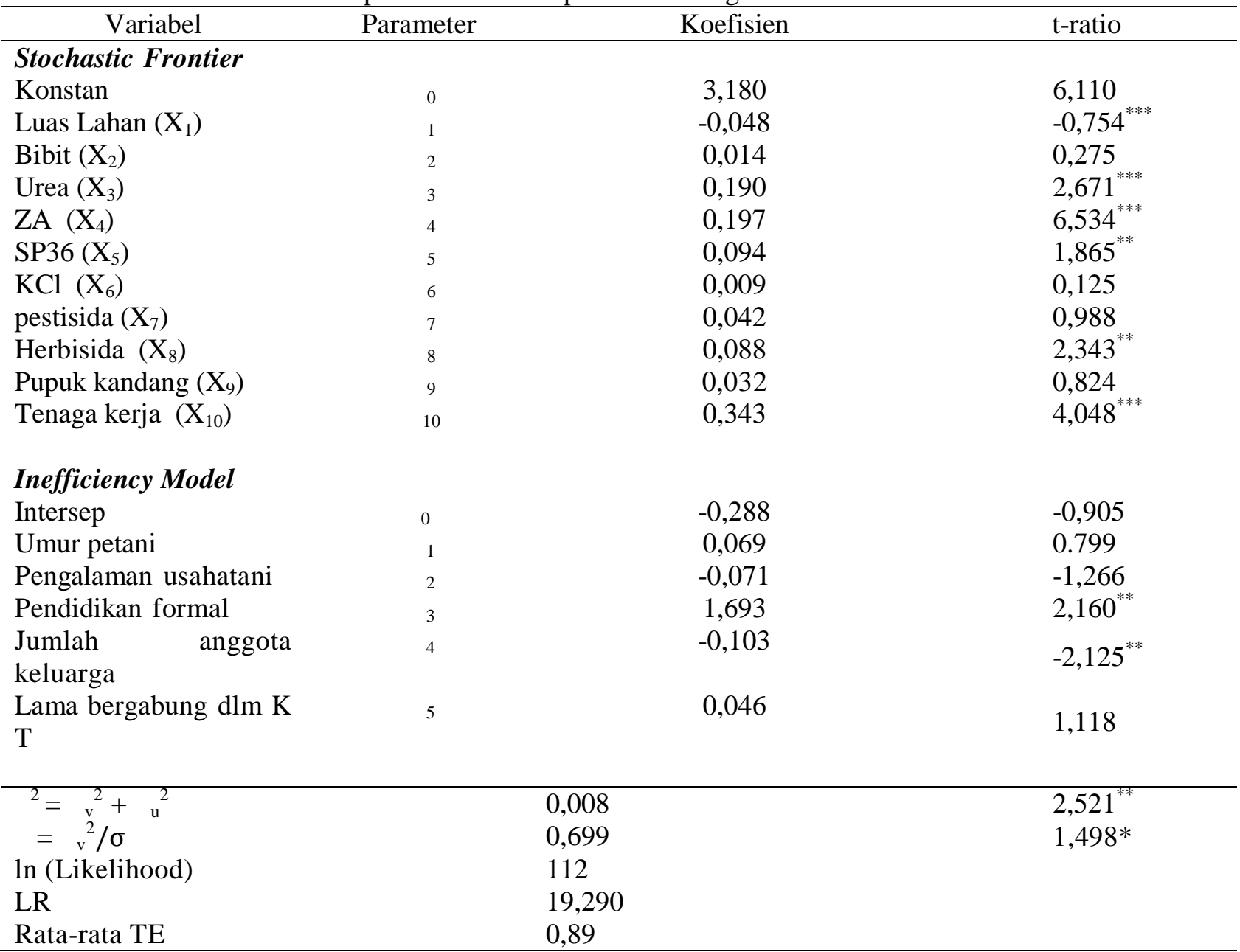

Sumber : Analisis Data Primer, 2012.

Keterangan: $* * *)=$ Signifikan pada taraf $\alpha=1 \%$

*) = Signifikan pada taraf $\alpha=10 \%$

Penambahan herbisida sebesar satu persen akan meningkatkan produksi sebesar 0,08 persen. Hal ini berarti meskipun efek peningkatannya kecil, hanya 0,08 persen namun penggunaan herbisida sangat penting karena memberikan dampak yang signifikan bagi produksi tanaman kopi hal ini disebabkan dengan penggunaan herbisida dapat menekan pertumbuhan gulma yang dapat menjadi pesaing tanaman dalam menyerap unsur hara dari dalam tanah.

Penggunaan tenaga kerja juga sangat berperan dalam peningkatan produksi kopi. Hal ini terlihat bahwa penggunaan tenaga kerja satu persen akan meningkatkan produksi sebesar 0,343 persen, cateris paribus. Meskipun peningkatannya tidak terlalu besar namun penggunaan tenaga kerja ini sangat berperan, utamanya dalam hal pemupukan dan pemanenan 
buah kopi.

\section{Analisis Efisiensi Teknis}

Efisiensi teknis dianalisis secara simultan dengan menggunakan model fungsi produksi stochastic frontier. Menurut Sumaryantono
(2001), nilai indeks efisiensi hasil analisis dapat dikategorikan belum efisien apabila nilainya $\leq$ 0,7 , dan dikategorikan efisien apabila nilainya $\geq$ 0,7 .

Tabel 2. Sebaran Efisiensi Teknis Usahatani Kopi Arabika di Kabupaten Enrekang

\begin{tabular}{|c|c|c|}
\hline Kelompok Efisiensi Teknis & Jumlah Petani (orang) & Persentase $(\%)$ \\
\hline $\mathrm{TE} \leq 0,70$ & 0 & 0,00 \\
\hline $0,70<\mathrm{TE} \leq 0,79$ & 4 & 4,00 \\
\hline $0,80<\mathrm{TE} \leq 0,89$ & 41 & 41,00 \\
\hline $0,90<\mathrm{TE} \leq 0,99$ & 55 & 55,00 \\
\hline Total & 100 & 100 \\
\hline Rata-rata TE & & 0,89 \\
\hline Minimum TE & & 0,78 \\
\hline Maksimum TE & & 0,98 \\
\hline
\end{tabular}

Sumber: Analisis Data Primer, 2012

Berdasarkan hasil yang dipaparkan pada Tabel 2 diatas terlihat bahwa dari sebaran nilai efisiensi teknisnya, sebagian petani responden $41 \%$ memiliki nilai efisiensi teknis pada kisaran 0,80 hingga 0,89 , dan sebagian besar petani berada pada kisaran 0,9 hingga dibawah 0.99 yaitu sebanyak 55 orang (55\%). Ini berarti bahwa secara keseluruhan petani kopi telah efisien secara teknis. Dari 100 responden petani yang ada, rata-rata efisiensi teknisnya adalah 0,89 . Ini berarti bahwa rata-rata petani telah dapat mencapai paling tidak 89 persen dari potensial produksi yang diperoleh dari kombinasi faktor produksi yang digunakan dan masih terdapat 11 persen peluang untuk meningkatkan produksi kopi.

Tingkat pencapaian efisiensi teknis usahatani kopi berdasarkan hasil penelitian tergolong tinggi. Pengalokasian sumberdaya dan penguasaan serta adopsi teknologi budidaya petani kopi sudah berada pada level yang sangat memuaskan. Efisiensi penggunaan input-input produksi masih dapat ditingkatkan untuk mencapai frontier tetapi dalam peningkatan yang relatif terbatas $(11 \%)$.

Hasil analisis sumber-sumber inefisiensi dengan metode MLE seperti terlihat pada Tabel 1 , ada variable yang berkorelasi negatif dan signifikan terhadap inefisiensi teknis usahatani kopi yaitu jumlah anggota keluarga petani. Adapula variabel yang berkorelasi positif dan signifikan terhadap inefisiensi teknis adalah pendidikan formal petani. Sementara variabel umur petani, pengalaman berusahatani, dan lama bergabung menjadi anggota kelompok tani tidak berpengaruh terhadap inefisiensi usahatani kopi.

Berdasarkan studi empiris maka tanda koefisien pada semua variable sumber-sumber inefisiensi teknis diharapkan negatif. Hasil menunjukkan bahwa pengalaman berusahatani memiliki tanda harapan negative tapi tidak berpengaruh nyata. Sedangkan variabel jumlah anggota keluarga memiliki tanda harapan negatif dan berpengaruh nyata terhadap inefisiensi kopi.

Peningkatan pendidikan berpengaruh nyata meningkatkan inefisiensi teknis usahatani kopi. Hasil ini tidak sesuai yang diharapkan karena berdasarkan studi empiris semakin tinggi pendidikan seseorang maka pengetahuan dan keterampilannya semakin meningkat sehingga dapat menurunkan inefisiensi teknis. Hasil analisis memperlihatkan bahwa semakin tinggi pendidikan petani responden maka semakin tinggi pula tingkat inefisiensi teknisnya. Hal ini diduga dengan semakin singkatnya tingkat pendidikannya maka semakin banyak dan lama waktu yang digunakan untuk menekuni usahataninya sehingga semakin efisien dalam mengalokasikan input usahataninya.

\section{KESIMPULAN}

1. Usahatani kopi yang dilakukan petani di Kabupaten Enrekang memiliki tingkat efisiensi teknis yang tinggi, yaitu rata-rata efisiensi teknisnya 0,89 . Faktor-faktor yang berpengaruh terhadap produksi tanaman kopi arabika adalah luas lahan, pupuk Urea, pupuk ZA, dan jumlah tenaga kerja.

2. Perlu pendampingan bagi petani dalam hal 
pengalokasian input pertanian dengan tepat, dalam hal ini penggunaan pupuk yang sesuai dosis dan anjuran agar diperoleh efisiensi teknis yang lebih tinggi dan produksi serta pendapatan yang lebih besar bagi petani.

\section{DAFTAR PUSTAKA}

Aigner, D.J., C. A. L. Lovell and P. Schmidt. 1977. Formulation and Estimation of Stochastic Frontier Production Function Models. Journal of Econometrics. 6(1): 2137.

Alam, 2006. Kelayakan Pengembangan Kopi Sebagai Komoditas Unggulan di Propinsi Sulawesi Selatan. Jurusan Sosial Ekonomi Pertanian Fakultas Pertanian Universitas Hasanuddin, Makassar.

Battesse, G.E., Corra G.S. 1977. Estimation of Production Frontier Model: With Application to the Pastoral Zone of Eastern Australia. Journal Agric. Econ. 21(3):169-179.
Coelli, T. J. 1996. A Guide to Frontier Version 4.1: A Computer Program for Stochastic Frontier Production and Cost Function Estimation. Centre for Efficiency and Productivity Analysis. University of New England-Armidale. New South Wales.

Coelli, T.J., D.S.P. Rao and G.E. Battese. 1998. An Introduction to Efficiency and

Productivity Analysis. Kluwer-Nijhoff. Boston.

Dinas Perkebunan Enrekang. 2005. Laporan Tahunan, Pengembangan Kopi di Sulawesi Selatan. Dinas Perkebunan Propinsi Sulawesi Selatan, Sulawesi Selatan.

Jondrow, J., C. A. K. Lovell, I. S. Materov and P. Schmidt. 1982. On Estimation of Technical Efficiency in the Stochastic Frontier Production Function Models. Journal of Econometric. 19(1982): 223-238.

Sumaryanto. 2001. Estimasi Tingkat Efisiensi Teknis Padi dengan Fungsi Produksi Frontir Stokastik. Jurnal Agro Ekonomi. 19(1). 